\title{
B2B Marketing Crafts Intelligence Commerce: How a Chatbot Is Designed for the Taiwan Agriculture Service
}

\author{
Abbott Po Shun Chen* \\ Department of Marketing and Logistics Management, Chaoyang University of Technology, Taiwan. \\ * Corresponding author. Email: chprosen@gm.cyut.edu.tw \\ Manuscript submitted September 23, 2019; accepted January 13, 2020. \\ doi: 10.17706/ijeeee.2020.10.2.114-124
}

\begin{abstract}
Intelligence commerce is one of the key success factors for Taiwan's development of business models. In particular, the agricultural service of rural areas is more like a social resource investment in the process of the transformation of the primary industry. However, agricultural firms still have to think about how to optimize services and create jobs to form an important resource base and competitive advantage. The place-making is the value of the circular economy, experience economy and digital economy provided by the intelligence commerce. The circular economy is the economic value of developing land recycling production. In remote farms, farmers' production processes and achievements can be assisted by customer communication and agile production visualization by the Chatbot of intelligence commerce, at which point the farm can be upgraded and added value. When consumers have prior knowledge and recognition of the farm, the farmers have a good stereotype, can provide services, and increase revenues for the experience activities of intelligence commerce. In view of the lack of information capacity of farmers, this research assists farmers in using a Chat to promote business activities. Overall, this research and the cooperative firm jointly develop intelligence commerce and establish an optimized business model for the practical application of a remote farmer's farm. In addition to the value of academic theory application, this achievement can also provide a good innovative operational value for industrial practice.
\end{abstract}

Key words: Intelligence commerce, Chatbot, value co-creation, agriculture service, B2B marketing.

\section{Introduction}

Intelligence commerce is one of the key success factors for Taiwan's development of business models. Intelligence commerce is Intelligent (Intelligence) E-Commerce, including intelligence e-commerce systems, artificial intelligence, main artificial intelligence applications for e-commerce, knowledge systems and their management, intelligent computerized personal assistants and their usability, knowledge of the Internet of Things, automatic Driving cars, intelligence homes and appliances, and intelligence cities [1]. This study applies intelligence commerce to the farm in the rural area.

The firm market creates and optimizes the business model of agricultural service, and improves the accuracy of agricultural B2B marketing performance. To develop new markets, cooperative firms need to focus on specific or weak markets in order to obtain the best market position for development [2]. Commercial service has become an important direction for the successful transformation of Taiwan's business. This also gives back to the commercial activities of agriculture. Whether the commercial activities of agriculture are transformed into service, but they still remain at the technological level. The change in the business model of the contemporary market also indicates that the agricultural business model also needs 
to change simultaneously. At this time, the farm is invested in agricultural service, the business model must be optimized, and the activity mechanism and performance of agricultural B2B marketing can be improved. In the age of data orientation, precision marketing is the development of business activities. Farms must change production patterns quickly. The farm uses market data to determine planting time and seed types. This brings accurate production and precise marketing to the farm.

The agricultural service in the rural areas of the rural areas is insufficient, and it is necessary to use intelligence to optimize its business model. The rural agriculture is the last glimpse of agricultural service and circulation. However, the fruit and vegetable markets and e-commerce platforms that are mainly oriented to market economic benefits are still aiming at the pursuit of economies of scale. When the government invests a lot of resources, it is easier to form a profit, and it may be difficult to convince public opinion representatives. And this last glimpse still has its economic value and importance. In terms of economic value, the farm is planted and produces high-value agricultural products, and its quality is also well received by the market. In the past decade or so, agricultural service has become a first-class industry for agriculture. Its added value has been improved, which has enabled many farms in intermediary towns to obtain good business results. In particular, the Council of Agricultural of the Executive Yuan (Taiwan Government) invests a lot of agricultural research and development every year, and through the technological innovation and introduction, the farm can be transformed successfully. In addition, many agricultural e-commerce platforms have been introduced, and the cities and towns have been activated. The electrician cooperates with the agricultural e-commerce to provide high-quality and stable supply to the agricultural e-commerce, to perform their duties and stabilize the e-commerce production and sales value chain of agricultural products [3].

This successful experience is more difficult to assist the rural areas ${ }^{1}$, mainly from the differences in farm characteristics are very different. For example, consumers go to experience the agricultural economy, and its geographical location is more difficult to obtain proximity. Furthermore, the farm operator's information interface is mainly based on mobile phones, and there are many obstacles to the use of desktop computers. Even agricultural products cannot have instant buyers. The main reason is that the existing e-commerce platforms are mainly dominated by platform operators, and the farms are less autonomy and less willing to invest in services. It can be seen that the operating characteristics of the rural townships have led to the use of existing agricultural e-commerce platforms on these farms. The lack of agricultural service shows that farms in rural areas cannot have a competitive advantage in the market, let alone real business performance. To this end, this study uses the cooperation unit to develop the rich experience and resource base of the e-commerce platform. Regarding the farms in the rural areas of the rural areas, the project host focuses on the lack of agricultural service and uses intelligence optimization to promote the introduction of intelligence commerce in the farms of the rural areas. And assist in obtaining complementary assets to form a competitive advantage in the market. This approach also creates a business model for innovative operations for agricultural firms and achieves new market creation and development of real estate profits. The purpose of this research is to build an intelligence commerce platform system and apply it to the innovative management of agricultural firms and farms, including agricultural production history, agricultural or farmer's official website, farm positioning and production, customer shopping, production and sales data analysis, online intelligent customer service assistant, and other intelligence commerce functions.

\section{Literature Review}

\footnotetext{
${ }^{1}$ Farms with remote geographical location and inconvenient traffic conditions, or farms with disadvantage market transactions.
} 
This research focuses on B2B e-commerce and intelligence applications of agricultural services, and provides academic development intelligence in e-commerce applications.

\subsection{B2B Commerce for Agriculture Service}

The e-commerce of agricultural products sales is divided into two categories [3], including

A. Integrated e-commerce platform, such as tw.buy.yahoo.com, https://mall.pchome.com.tw, https://www.books.com.tw, etc., but the turnover of agricultural foods is not high; it is sold by e-commerce platform, or the platform is provided by the manufacturers or farmers who are stationed.

B. Vertical e-commerce platform, like agricultural products stores, selling products mainly based on agricultural products, and some may sell other agricultural-related commodities, such as rural tourism, rural handicrafts and other agricultural related products, etc., defined as "Agricultural E-commerce". Roles that can be subdivided into identities include

1) Farmers' groups: The operators are agricultural and fisheries organizations or farmers' groups. For example www.ubox.org.tw, www.efarm.org.tw, www.buy.org.tw, www.fishermart.com.tw, etc.

2) Agricultural firms: The operators are agricultural firms, and the products are mostly self-produced or sold under their own brands. In order to expand the original sales channels, another shopping cart is set up on the existing official website to directly sell to consumers, such as shop-gugugoo.demo.thrive.tw, www.liyuanfarm.com.tw, shop,kky.com.tw, etc., but most of the online gold flow is incomplete, and can only provide payment functions such as cash on delivery or transfer.

3) Entity access: The operator is the entity channel operator, and expands the original sales channel, sets up an e-commerce platform, and integrates online and offline resources, such as www.taisugar.com.tw, www.natural-house.com.tw, www.anyongfresh.com, www.leezen.com.tw, etc.

4) Internet firms: operators are Internet marketing firms or those who are not engaged in agricultural production but are interested in marketing of agricultural products. Compared with other types, this type of e-commerce is good at Internet marketing and utilizing various network resources. The number of arrivals has increased substantially, which is the mainstream of agricultural e-commerce such as www.wonderfulfood.com.tw, www.buydirectlyfromfarmers.tw, sojourn.tw, etc.

The agricultural production and marketing information has exerted tremendous impetus and far-reaching influence on the development of Taiwan's agricultural economy, such as the integration of agricultural environmental resources by ICT, and the improvement of agricultural production and marketing mechanisms [4]. At present, the agricultural administrative organs have regularly investigated the production materials such as crops, food, fishery, livestock, and processing, and used computers to accelerate data collection, transmission, and statistical analysis. In addition, it actively assists farmers in applying the "production and sales operation management system" to record the production process, control the use of materials, understand the required costs and conduct account processing through information systems to help farmers improve their management efficiency. However, due to the current lack of awareness and application of information technology in Taiwanese farmers, the provision of comprehensive production information has not been instantaneous, which has led to the occurrence of imbalances in production and sales. Therefore, how to effectively use the "production and sales management system" and the agricultural information highway established by the Agriculture and Fisheries Association's "Agricultural Information Network" to collect production-related information through a real-time collection mechanism. Only by mastering the production status of various agricultural products in advance can we formulate an effective marketing strategy.

Establish a complete database of agricultural production surveys, market transactions, agricultural products and trades with accurate information, and establish a production and sales analysis decision 
support system. Combine the system information with a comprehensive view, and establish a production and sales model by industry or geographical analysis. Provide agricultural operators to improve operational performance indicators, and then develop production and sales early warning mechanisms to reduce the risk of imbalance between production and sales, which is an important measure for the future application of agricultural information in production and marketing adjustment. Another example is the use of information technology to assist in the development of agricultural value chain management. After Taiwan's accession to the WTO, Taiwan's agriculture has entered the global market competition. How to avoid price competition with foreign agricultural products and develop differentiated and irreplaceable products or services to strengthen competitive advantage is the current and important topic in agricultural development. Micahel Porter stated in a Taiwan's speech in April 2000 that the value chain is based on the value of the consumer's internal material and technical value activities. With margin, and information technology is an important tool throughout the industrial value chain. The transmission and application of information can stimulate the research and development, design, and new services and marketing of new products, so that the value chain can be integrated.

E-commerce has been widely used in agricultural production, cultivation management, marketing, etc., and can provide more farmers' partners who are interested in production and marketing information. Although the production and marketing environment of small farmers is limited, it can be cultivated. The management introduces diversified production models, makes full use of existing resources, improves production efficiency, and then uses different functions of services or community platforms for marketing. It will be able to use blogs or Facebook to record the details and mentality of daily cultivation management. The embarrassing mood not only allows consumers to better understand the intentions of farmers but also enhances visibility, establishes a diversified sales channel and brand image [5]. In addition, the production of smaller farms can be compared with online retail, the combination of information brokers, online market and other electronic platforms can provide a way to meet today's consumer demand and expand business opportunities beyond traditional sales channels. In recent years, the COA has actively promoted the integration of production and sales resumes and information on Jiyuan and has gradually raised the value-added benefits of agricultural production to a certain level. How to show the benefits of the value-added of commodities, it is necessary to continue to promote the informationization of agricultural production and marketing and use various e-commerce platforms to develop a more active and forward-looking production and marketing system. The core axis of Taiwan's agricultural business promotion is based on the existing infrastructure and continues to introduce capital communication technology. It is expected to establish an agricultural cloud environment and fully collect and analyze various information and data to make the overall agricultural development [3]. And using the ever-changing network computing capabilities can be provided by agricultural policymakers, agricultural producers, and consumers with more information. Those rich and informative information attracts more people and young partners who are interested in farming. The traditional new industry of the foundation industry.

\subsection{Intelligence in B2B Commerce}

E-commerce is developing in intelligence applications. For example, firms develop a set of fruit mature image recognition systems that can be used by farmers. The system recognizes whether the fruit in the picture is mature by capturing the image taken by the imaging lens. The data is passed back to the system for subsequent processing to open the front end for Productivity 4.0 Technology Agriculture. The recognition mode divides the identification problem into three parts: detection, segmentation, and recognition. The detection means that the image to be recognized is imaged by the image capturing device to find the feature point of the object. After the capture is completed, the object is cut, that is, the feature point description is described by a local patch of the feature point, and the described method is called a 
descriptor. Finally, enter the identification, will be classified according to the set classifier [6]. In terms of website architecture, virtual space has virtual information space, virtual communication space, virtual distribution space, and virtual transaction space to analyze the website structure of leisure farms. The leisure farms on both sides of the strait are still dominated by industrial resources, and the comprehensive utilization type is second. However, those who use the cultural resource utilization type as the management feature are not. After the implementation degree and cluster analysis, it is found that the cross-strait leisure farm websites are mostly guided by virtual information space. The display is still at the level of introducing the farm, and the virtual distribution space and e-commerce functions such as virtual trading space still have room for development. Overall, the leisure farm website in Taiwan is relatively complete in terms of functional architecture, and it also pays attention to security and privacy [7].

\section{Research Method}

The design and construction method of information platform system for intelligence commerce. In the design of scientific system design method, this study refers to the host's past related research [8], mainly to build an intelligence commerce information platform system. According to the needs of business interviews, the intelligence commerce is including information confidentiality agreement signing, system construction Inter-layer bridging solutions and information security solutions with corrections, firm import barriers, firm existing systems and e-commerce platforms. This study refers to the interfirm synergy [9], including the highly uncertain phenomenon of technology and market, and the formation of clustering synergy. It is regarded as a kind of technologically systematic linkage and clustering synergy innovation. More effective than the development alone. Through the technical cooperation foundation, firms have greater economic incentives and profits, and the platform transparency between joint supervision and cooperation can make the synergy have better mutual trust value. This study also uses the systematic development research methodology developed by [10] as the development step of this research system. The research process consists of the following five main steps: constructing a conceptual framework, developing a system architecture, analyzing and designing systems, building a prototype system, and observing and evaluating systems.

\subsection{Construct a Conceptual Framework}

This step is based on the results of interviews with farms, cooperative firms and consumers as the conceptual framework for this research.

\subsection{Development System Architecture}

In the context of the system conceptual framework requirements, this research reference explores the architecture of the system with the moderator [8], and develops the preliminary architecture of the prototype system.

\subsection{Analysis and Design System}

This includes system functions, analysis content, and functional design. The system integrates multi-language features (such as ASP.NET MVC 4, C\#, HTML 5), multi-person support, and security and bug fix databases (such as Microsoft SQL Server) and applications. In addition, firms need to have an application server, which can mainly provide application configuration settings, set security functions and reduce network attacks. Especially in the user management interface, the expansion module can be easily managed and flexibly.

\subsection{Establishment of the Prototype System}


This step is based on the system architecture and analysis designed and developed according to the above three steps, detailed planning system architecture and process, and implementation of the prototype system. Among them, development platforms (such as Visual Studio 2012, Net Framework 4.5) and support platforms (such as Windows, iOS, Android, Mac, Browser need support IE 9+, Chrome, Firefox, Safari, and web function development to be compatible with IE 9+, Chrome, Firefox, Safari, based on no problems) is also a key factor in building. GPS positioning uses the Google system. The intelligence customer service system uses the A Neural Conversational Model of [11]. Dialogue modeling is an important task of natural language understanding and machine intelligence. Although previous methods exist, they are usually limited to specific domains (such as booking a ticket) and require hand-made rules. Using the sequence-to-sequence (seq2seq) architecture [12], they proposed a simple way to accomplish this task, which uses the recently proposed sequence to sort the framework. For example, the model talks by predicting the next sentence of a sentence in a given sentence or sentence. The advantage of this model is that it can be trained end-to-end, so fewer manual rules are required.

This simple model can generate a simple conversation given a large dialog training data set. This model works well for conversations when optimizing the wrong objective function. It extracts knowledge from domain-specific data sets and extracts knowledge from large, noisy, and common domain data sets of movie subtitles. On the dataset of the domain-specific IT help desk, this model can find solutions to technical problems through dialogue. On a noisy open-field movie transcript dataset, this model can perform simple forms of common sense reasoning. Suppose we observe two rounds of dialogue: the first person says "ABC" and the second person answers "WXYZ". We can use recursive neural networks and train to map "ABC" to "WXYZ". When the model receives the end of the sequence symbol "<eos $>$ ", the hidden state of the model can be thought of as a thought vector because it stores the information of the sentence or the idea "ABC". The advantage of this model is its simplicity and versatility. We can use this model for machine translation, questions/answers and conversations without major changes to the architecture. Applying this technique to conversation modeling is also simple: the input sequence can be a concatenation of the content (context) that has been converted so far, and the output sequence is a reply.

\subsection{Observation and Evaluation System}

After the completion of the prototype system, the effectiveness of the system is observed and evaluated by the system content, system operation capacity limitation, and operational efficiency. To capture systemic risk, this study focuses on risk [13] [14] and guidelines [15]. The first is technical risk. This study will control the complete measurement mechanism, software code detailed inspection and software version control and modification. Again, cloud risk, the cloud is one of the most useful technical tools. Users need an audit log function design. All users should have a role that defines the responsibilities of the person. In order to comply with ISO 27001 requirements, this study needs to meet the cloud application management mechanism and extend the periodic implementation of scanning and penetration testing system vulnerabilities. Finally, there is user risk. The user account should have a management mechanism. The password must be set to more than 8 English numbers. Personal data processing in the system is designed according to the rules of the personnel data. Therefore, the system and data of this study can be effectively managed.

Big data analysis of quantitative research. This study uses user-use value data collection. This study refers to [8] and [16], and uses Google Analytics to collect and analyze the differences between users' current conditions and operating efficiency. Finally, this study will use the collected data to find out the best marketing characteristics, which can provide the firm B2B marketing practice, and develop the demonstration case of the algorithm in B2B marketing. 


\section{Results}

The results of this study include the analysis of the use of existing technologies, the assessment of product market demand and competitiveness, and the planning of Chatbot.

\subsection{The Analysis of the Use of Existing Technologies}

The recognition of organic agricultural products is not the most important factor affecting the willingness to use and the behavior of use. Internet accessibility perception has the greatest impact, followed by usefulness perception, and the impact of organic agricultural product recognition is minimal. The two groups of respondents who had significant differences in organic agriculture exposure or recognition were organic agricultural e-mail subscribers and school faculty members, arguing that the ratio of online home delivery to the ideal pipeline for purchasing organic agricultural products was as high as $10 \%$ and $14 \%$ respectively. It shows that the prospect of online trading of organic agricultural products can be expected [17]. A comparison of the e-commerce information platform system is shown in Table 1.

Table 1. Comparison of the Intelligence Application of e-Commerce Information Platform System Technology

\begin{tabular}{|c|c|c|}
\hline Item & Agriculture Intelligence Commerce & Agriculture E-commerce \\
\hline Produce source & Rural Farm & Farm in a city or an intermediary town \\
\hline $\begin{array}{l}\text { (1) Deep } \\
\text { technology }\end{array}$ & $\begin{array}{l}\text { Yes, neuro-intelligent customer service } \\
\text { dialogue model }\end{array}$ & None \\
\hline (2)ICT application & Yes, GPS positioning and record & None \\
\hline (3)Big date analytics & $\begin{array}{l}\text { Yes, use Google Analytics to monitor and } \\
\text { control autonomic analysis and forecasting }\end{array}$ & $\begin{array}{l}\text { Yes, some platforms use Google Analytics } \\
\text { to monitor and master simple narrative } \\
\text { statistical analysis. }\end{array}$ \\
\hline
\end{tabular}

This research has the advantage of being more in line with the existing intelligence application, providing the technology application of the farm directly into the business intelligence, without using the existing desktop computer platform, directly operating by mobile phone, and also meeting the farmer's information operation ability and identification ability. The similar functions are between intelligence commerce and E-commerce as follows. Online shopping carts often use credit card swipe functions, mobile payment functions, and cash on delivery functions in cash flow. Online logistics services use existing logistics firms to serve consumers, such as home delivery, post office.

Product information has product features, photos, production information. Social media has a combination of LINE, Facebook and WeChat.

\subsection{The Assessment of Product Market Demand and Competitiveness}

In view of this research, we focus on the farms of the high mountains and establish agricultural intelligence business. This will compare existing agricultural e-commerce farms with farms in metropolitan or intermediaries. The following is an assessment of the market demand and competitiveness (cost) of the research product. See Table 2.

Table 2. The Assessment of Product Market Demand and Competitiveness

\begin{tabular}{lll}
\hline \hline Item & Agriculture Intelligence Commerce & Agriculture E-commerce \\
\hline Produce source & Rural Farm & Farm in a city or an intermediary town \\
\hline Product market demand & & \\
\hline Farm location GPS & $\begin{array}{l}\text { Establish GPS positioning through intelligence } \\
\text { location visualization }\end{array}$ & None \\
& $\begin{array}{l}\text { business, and guide the farm to establish visual } \\
\text { information }\end{array}$ &
\end{tabular}




\begin{tabular}{|c|c|c|}
\hline $\begin{array}{l}\text { Farm environment } \\
\text { visualization record }\end{array}$ & $\begin{array}{l}\text { Establish a record interface for mobile phones } \\
\text { through intelligence business, and guide the } \\
\text { farm to establish visual information on its own }\end{array}$ & None \\
\hline $\begin{array}{l}\text { Production history } \\
\text { visualization record }\end{array}$ & $\begin{array}{l}\text { Establish a production process interface for } \\
\text { mobile phones through intelligence business, } \\
\text { and guide the farm to establish visual } \\
\text { information on its own. }\end{array}$ & None \\
\hline Product quality & Products have their own distinctive appearance & Product is consistent appearance \\
\hline $\begin{array}{l}\text { Product to the } \\
\text { government visual } \\
\text { record }\end{array}$ & $\begin{array}{l}\text { Guide the farm to establish visual information by } \\
\text { establishing a record interface for product } \\
\text { arrival through intelligence business }\end{array}$ & None \\
\hline Online customer service & Intelligence customer service & Canned language service, human service \\
\hline \multicolumn{3}{|l|}{ Competitiveness (cost) } \\
\hline $\begin{array}{l}\text { Low pollution } \\
\text { environmental cost }\end{array}$ & Achievable & Hard to reach \\
\hline Low production cost & Achievable & Hard to reach \\
\hline Co-specificity assets & $\begin{array}{l}\text { Intelligence commerce and farm maintain } \\
\text { mutual brand }\end{array}$ & $\begin{array}{l}\text { E-commerce and farms develop } \\
\text { individual own brands }\end{array}$ \\
\hline Complementary assets & $\begin{array}{l}\text { Intelligence commerce and farm } \\
\text { interdependence }\end{array}$ & E-commerce dominant rules \\
\hline Value co-creation & $\begin{array}{l}\text { Intelligence commerce and farms have a } \\
\text { common goal to quickly achieve common } \\
\text { business value }\end{array}$ & $\begin{array}{l}\text { E-commerce and farms have their own } \\
\text { goals, which can balance self-resources } \\
\text { and develop self-worth }\end{array}$ \\
\hline
\end{tabular}

\subsection{The Planning of a Chatbot}

Artificial intelligence applications are mainly to assist farmers in the lack of communication skills or in place, can be divided into two ways. Frequent customer questions: The adoption of rules is based on response and learning responses are supplemented. The main reason is to stabilize common words first, and gradually correct them to accuracy through generating calculus. In addition, professional questions are based on regular responses, mainly based on professional words and fixed application words. The project uses the more mature chatbot structure as a development test, and recognizes the basic knowledge of the construction of chatbots, and the results of testing.

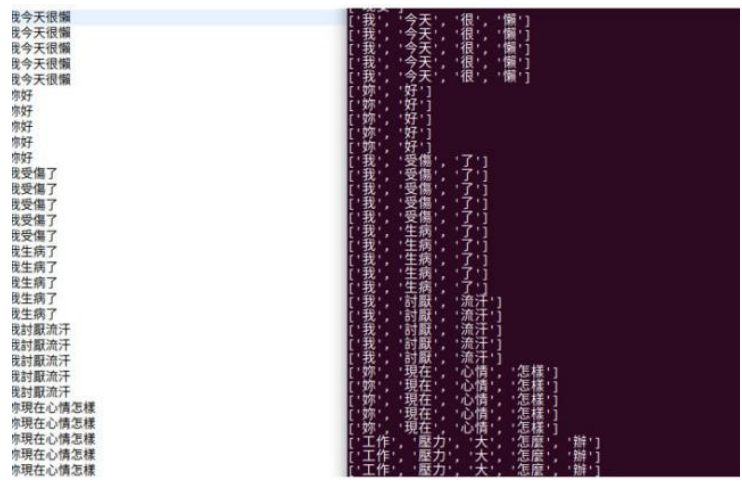

Fig. 1. The example results of the Chatbot.

First, this study addresses the loading and pre-processing of the Cornell Movie-Dialogs Corpus dataset. Again, this study uses the Attention Mechanism to implement the Seq2seq model. Third, this study uses a batch training encoder and decoder model. The machine learning results are shown in Figure 1. 


\section{Conclusion}

The diversified natural resources and products of agriculture are important reasons for the creation of the firm development market. When agribusiness establishes key success factors for innovative services and operations, intelligence commerce can provide job flexibility and process agility and build unique. The purpose of this research is to build a dedicated intelligent commerce platform system for farm operations and to include a GPS positioning system and intelligence customer service system. This research assists cooperative firms to develop intelligence commerce platform systems, and also provides them to the farms for innovative operations. This innovative business includes agricultural optimization and place-making. Agricultural optimization is the function of the farmers based on the intelligence commerce platform system, calibrating and increasing the intelligence of customer service, enhancing the customer's attention to the adhesion and the optimal product portfolio.

The results of this research include cultivating the research and development potential of the firm, guiding the cooperative firm to establish an intelligence business platform system, establishing a farm-in-the-earth creation service model of the rural township, and guiding the firm and the farm development of 25 rural farms. Service and establish a partnership.

In the fruits of corporate value, firms and farms jointly promote intelligence business platforms. This will enhance the added value of products and the performance of management services, increase the value of cooperative firms by NT\$8 million, and guide cooperative firms to establish a farm-specific demonstration innovation operation for the development of e-commerce in agriculture and the development of agricultural business in rural areas. This establishes a co-creation model of service values for farm creation. In terms of technology application, the research results combine ICT and intelligence on the e-commerce platform to develop intelligence business with exemplary and standard, apply GPS positioning system to the farm and develop intelligence customer service system with deep learning calculus.

\section{Conflict of Interest}

The author declares no conflict of interest.

\section{Acknowledgment}

The author thanks the editors and anonymous reviewers. This research was supported by grants from the Ministry of Science and Technology, Taiwan, R. O. C. (MOST 107-2637-H-324-001-, Co-Creating B2B Marketing and Values: Inter-firms Craft Business Intelligence System; MOST 108-2745-8-324 -001-, Applying Intelligence Commerce Crafts the Business Model of Taiwan Agriculture Optimization and Revitalization).

\section{References}

[1] Turban, E., Outland, J., King, D., Lee, J. K., Liang, T. P., \& Turban, D. C. (2018). Intelligent (intelligence) e-commerce. Electronic Commerce, 249-283.

[2] Teece, D., Peteraf, M., \&Leih, S. (2016). Dynamic capabilities and organizational agility: Risk, uncertainty, and strategy in the innovation economy. California Management Review, 58(4), 13-35.

[3] Council of Agriculture, Executive Yuan. (2016). Current situation of agricultural products e-commerce development in Taiwan and its administrative prospects. Agricultural Policy and Agricultural Situation, 283.

[4] Lin, B. (2006). The current situation of Taiwan's agricultural production and marketing information. Crop, Environment and Biological Information, 3(1), 33-39.

[5] Wu, C. Y. (2012). Introduction to the application of e-commerce in agricultural marketing. Taidong 
District Agricultural Journal, 81, 21-25.

[6] Chen, Y. S., Cao, H. H., Chen, S. W., Liu, C. Y., \& Ye, L. G. (2018). Study on fruit ripening by image recognition technology. Electronic Commerce Studies, 16(3), 233-257.

[7] Lin, J. N., Shi, M. L., Chen, W. Y., \& Huang, B. W. (2009). Application content analysis and cluster analysis method to evaluate cross-strait leisure farm website. Taiwan Agricultural Society, 10(3), 197-213.

[8] Chen, P. S., \& Huang, P. C. (2017). Integrated marketing communication: Use information technology connects three dyad relationships. International Journal of Applied Business and Economic Research, 15(20), 87-99.

[9] DeBresson, C., \& Amesse, F. (1991). Networks of innovators: A review and introduction to the issue. Research Policy, 20(5), 363-379.

[10] Nunamaker, J. F., Chen, M., \& Purdin, T. D. M. (1990). Systems development in information systems research. Journal of Management Information Systems, 7(3), 89-106.

[11] Vinyals, O., \& Le, Q. V. (2015). A Neural Conversational Model.

[12] Sutskever, I., Vinyals, O., \& Le, Q. V. (2014). Sequence to Sequence Learning with Neural Networks.

[13] Charani, E., Castro-Sánchez, E., Moore, L. S., \&Holmes, A. (2014). Do intelligence phone applications in healthcare require a governance and legal framework? It depends on the application! BMC Medicine, 12(1), 29.

[14] Barki, H., Rivard, S., \& Talbot, J. (1993). Toward an assessment of software development risk. Journal of Management Information Systems, 10(2), 203-225.

[15] Ross, R., McEvilley, M., \& Oren, J. (2018). Systems security engineering: Considerations for a multidisciplinary approach in the engineering of trustworthy secure systems (No. NIST Special Publication (SP) 800-160 (Withdrawn)). National Institute of Standards and Technology.

[16] Chen, A. P. S., \& Wang, J. H. (2018). Is B2B marketing enable in value-in-use? The co-creation perspective. Proceedings of 4th International Conference on Business and Engineering Research. Osaka, Japan.

[17] Huang, R. R., \&Shi, J. F. (2004). The acceptance of e-commerce for organic agricultural products by consumers. Journal of Humanities and Management, 1, 247-273.

Copyright (C) 2020 by the authors. This is an open access article distributed under the Creative Commons Attribution License which permits unrestricted use, distribution, and reproduction in any medium, provided the original work is properly cited ( $\underline{\text { CC BY 4.0). }}$.

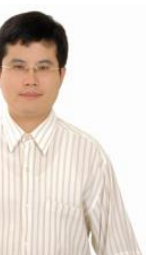

Abbott Po Shun Chen was born in Taiwan. He holds PhD candidate of at National Central University and got a master degree at National Chung Cheng University in 2003. He is an assistant professor for Dept. of Marketing and Logistics Management, the Chaoyang University of Technology (THE 1001+, 2019). And he also is an entrepreneurship consultation, 14 years to now, small and medium firm administration, Ministry of

Economic Affairs, Taiwan.

His research area is including B2B marketing, Information Management, Entrepreneurship, Business Intelligence.

His five current journal papers were How B2B marketing makes a decision for value co-creation? (2019), How B2B partnerships craft value relations? (2019), Crafting value co-creation: Is learning entrepreneurship in normal courses unuseful dilemma? (2018), Crafting interfirm supply chain management: The communication role of information system (2017), and Integrated marketing communication: Use information technology connects three dyad relationships (2017). Secondly, his four 
current conference papers were The APP transfers withdrawal real-time message: The salvage products for consumers (China: Excellent Oral Presentation Award, Southwest Jiaotong University, 2019), Is B2B marketing enable in value-in-use? The co-creation perspective (Japan: Best Paper Award, IPN, 2018), Crafting augmented the reality in learning: A co-creation perspective (Indonesia: Yogyakarta State University, 2018) and A medical co-creation system crafts B2B marketing (Japan: University of Tsukuba, 2018). Thirdly, his four technology transfer cases were Applying Intelligence Commerce Crafts the Business Model of Taiwan Agriculture Optimization and Revitalization (Dah Chwan Digital Technology Co. Ltd, 2019), Business intelligence (BI) for cross supply chain integration system (Long Tai Copper Corp., 2017), Business intelligence and marketing innovation service system (Dah Chwan Digital Technology Co. Ltd, 2017) and Customized craniofacial plastic implants for innovative service (Hanlix International Co. Ltd., 2014-15).

His two current international academic services were a speaker of 2nd ICSSED International Conference of Social Sciences and Education (Indonesia: Yogyakarta State University) and a reviewer of 2017-2019 Personnel Review (SSCI).

His current research interest is including B2B marketing for the Association of Southeast Asian Nations (ASEAN) and Artificial Intelligence for E-commerce and customer services, such as the Chatbot. 